\title{
ANÁLISE DA MARTENSITA INDUZIDA POR DEFORMAÇÃO DE UM AÇO INOXIDÁVEL AUSTENÍTICO 304L COM CONCENTRADORES DE TENSÃO SUBMETIDO A FADIGA DE BAIXO CICLO
}

Jéssica Gadêlha Chaves '

Gláucio Soares da Fonseca ' Luiz Carlos Rolim Lopes '

\section{Resumo}

Os aços inoxidáveis austeníticos metaestáveis sofrem transformações de fase de microestrutura austenítica para martensítica quando sujeitos à deformação a frio, melhorando significativamente sua resistência mecânica (efeito TRIP). A transformação é influenciada pela temperatura, composição química, taxa de deformação e estado de tensões durante a deformação. Para compreender a transformação martensítica no AISI 304L, foram analisadas amostras com e sem descontinuidade circular submetidas a esforços cíclicos. Existem poucos trabalhos relacionando a transformação martensítica com estes tipos de esforços, e em muitos casos, estes aços estão submetidos a este carregamento. A análise da martensita $\alpha^{\prime}$ foi feita através de ferritoscopia e sua morfologia obtida via microscopia ótica. Os resultados mostraram para a amostra sem descontinuidade circular, que ocorre uma saturação da deformação e os laços de histerese ficaram sobrepostos, não havendo a necessidade de um elevado número de ciclos para se obter uma deformação em torno de 0,10 e uma fração volumétrica de martensita entre 6 e 7\%. Após ensaio de fadiga em diferentes frequências para amostras com descontinuidade circular notou-se que em frequências menores, as amostras apresentam próxima a descontinuidade circular maiores frações volumétricas de martensita, pois o trabalho da deformação é menor, sendo assim sofrem menos com o efeito da temperatura que tende a inibir a transformação de fase.

Palavras-chave: Aço inoxidável austenítico 304L; Efeito TRIP; Fadiga de baixo ciclo; Transformação martensítica.

\section{ANALYSIS OF THE STRAIN-INDUCED MARTENSITE OF A 304L AUSTENITIC STAINLESS STEEL WITH STRESS CONCENTRATORS SUBJECTED TO LOW CYCLE FATIGUE}

\begin{abstract}
The metastable austenitic stainless steels undergo phase transformations of austenitic microstructure for martensitic when subjected to cold deformation, significantly improving its mechanical resistance (TRIP effect). The transformation is influenced by the temperature, chemical composition, deformation rate and tensions states during deformation. In order to understand the martensitic transformation in AISI 304L, samples with and without circular discontinuity and cyclic load were analyzed. There are few works relating the martensitic transformation to these types of stress state, and in many cases, these steels are subjected to this loading. The analysis of $\alpha^{\prime}$ martensite was done by means of the ferritescope and its morphology obtained by optical microscopy. The results showed for the sample without circular discontinuity, that a deformation saturation occurs, and the hysteresis loops were superimposed, not requiring a high number of cycles to obtain a deformation around 0.10 and a volume fraction of martensite between 6 and $7 \%$. After fatigue test at different frequencies for samples with circular discontinuity, it was noticed that in the lower frequencies, the samples presented near the circular discontinuity greater volumetric fractions of martensite, since the deformation work is smaller, undergoing thus less with the effect of the temperature which tends to inhibit phase transformation
\end{abstract}

Keywords: 304L austenitic stainless steel; TRIP effect; Low cycle fatigue; Martensitic transformation.

'Universidade Federal Fluminense - UFF, Volta Redonda, RJ, Brasil.E-mail: gadelhach@gmail.com 


\section{INTRODUÇÃO}

Os aços inoxidáveis são ligas contendo $\mathrm{Fe}, \mathrm{C}$ e $\mathrm{Cr}$, e apresentam características como: excelente resistência à corrosão, boa soldabilidade e propriedades mecânicas [1,2]. São classificados com base na sua microestrutura a temperatura ambiente, em: martensíticos, ferríticos, austeníticos, ferrítico-austeníticos (duplex) e endurecidos por precipitação [I].

Os austeníticos podem ainda ser classificados de acordo com o efeito da deformação a frio, em: austeníticos estáveis e metaestáveis. Os austeníticos estáveis são aqueles que mantêm a estrutura austenítica (CFC), mesmo após a aplicação de acentuada deformação a frio e os metaestáveis são os que transformam a estrutura austenítica para martensítica (CCC) quando sujeitos à deformação a frio em temperaturas abaixo da temperatura máxima de formação de martensita (Md) [I]. A transformação martensítica depende da temperatura, da composição química do material, do estado de tensão e da taxa de deformação sobre o material durante a deformação [2].

Em ensaios onde as taxas de deformação são de moderadas a elevadas, a quantidade de martensita é menor, assim, a fração volumétrica de martensita diminui com o aumento da taxa de deformação, devido ao efeito da temperatura, que conforme aumenta inibi a transformação, concluindo-se que o aumento da estabilidade da austenita resultou do aquecimento adiabático a taxas altas [2,3]. Os aços inoxidáveis austeníticos são suscetíveis à transformação via deslocamento de planos atômicos, podendo se formar dois tipos distintos de martensita: martensita $\varepsilon$, uma fase paramagnética, apresentando estrutura hexagonal compacta $(\mathrm{HC})$, e martensita $\alpha$, ferromagnética, apresentando estrutura cúbica de corpo centrado (CCC). A transformação martensítica está relacionada com a energia de defeito de empilhamento (EDE), um parâmetro influenciado pela temperatura e composição química da austenita [4]. Forma-se martensita por deformação porque a energia necessária para esta transformação é menor que a energia necessária para formar maclas de deformação.

Quando a deformação é aplicada, a seguinte sequência de transformação é obtida: $(\gamma) \rightarrow(\varepsilon) \rightarrow\left(\alpha^{\prime}\right)$, porém, a fase $\mathrm{HC}$ pode não atuar como fase intermédia, se a composição é alterada de tal modo que a energia de defeito de empilhamento é aumentada [5]. A fase $\varepsilon$ também se forma em baixas temperaturas na ausência de deformação plástica, enquanto para a formação de $\alpha$, a deformação plástica é necessária [6].

A faixa de temperatura em que a transformação ocorre situa-se entre Ms, temperatura crítica, que corresponde ao aparecimento da martensita térmica e $M d$, máxima temperatura para a formação da martensita, onde a austenita é termodinamicamente instável na presença de tensão. Esta reação tem características atérmicas e adifusionais, na qual os átomos se movimentam de forma coordenada e cooperativa por um mecanismo de cisalhamento e essa transformação ocasiona um aumento substancial da densidade de defeitos cristalinos, que produz uma microestrutura com alta resistência mecânica e a força mecânica aplicada aumenta a energia livre de Gibbs [7].

Segundo Maier et al. [8] que investigaram a transformação de fase induzida por fadiga em um AISI 304L ensaiado a baixas temperaturas, $-170^{\circ} \mathrm{C}$ e $-70^{\circ} \mathrm{C}$, eles observaram que a taxa de formação de martensita aumenta com a diminuição da temperatura, no entanto a fração volumétrica máxima de martensita $\alpha$ ' adquirida em ambas as temperaturas permanecem praticamente as mesmas, e o aumento da amplitude da tensão cíclica durante a deformação é determinada principalmente pela quantidade de martensita $\alpha$ ', e ainda segundo os autores a deformação cíclica pode dar um volume de martensita máximo superior à deformação monotônica. Zhang et al. [9], analisaram a transformação martensítica induzida por deformação em um AISI 304L submetido à carregamento e descarregamento em tração cíclica através da difração de raio-x in situ, em comparação ao carregamento de tração monotônico convencional. Concluíram que o carregamento e descarregamento de tração cíclica aumentou o encruamento e também a fração volumétrica de martensita induzida por deformação em relação ao carregamento monotônico tradicional, consequentemente aumentando o efeito TRIP. Eles mostraram que o teor de martensita aumenta após cada descarregamento em grandes deformações devido à alteração da estrutura interna que envolve a tensão interna e configuração das discordâncias quando o descarregamento ocorre.

É bem conhecida que descontinuidades, entalhes, etc., produzem concentradores de tensão [10]. A Figura I apresenta $\circ$ efeito de uma descontinuidade circular na tensão local, chegando ao valor de $3 x$ a tensão nominal $(\sigma)$. Neste trabalho foi analisada a martensita $\alpha$ ' produzida em amostras de um AISI 304L sem e com concentradores de tensão, ensaiadas ciclicamente através de controle por carga e controle por deformação. Existem poucos trabalhos

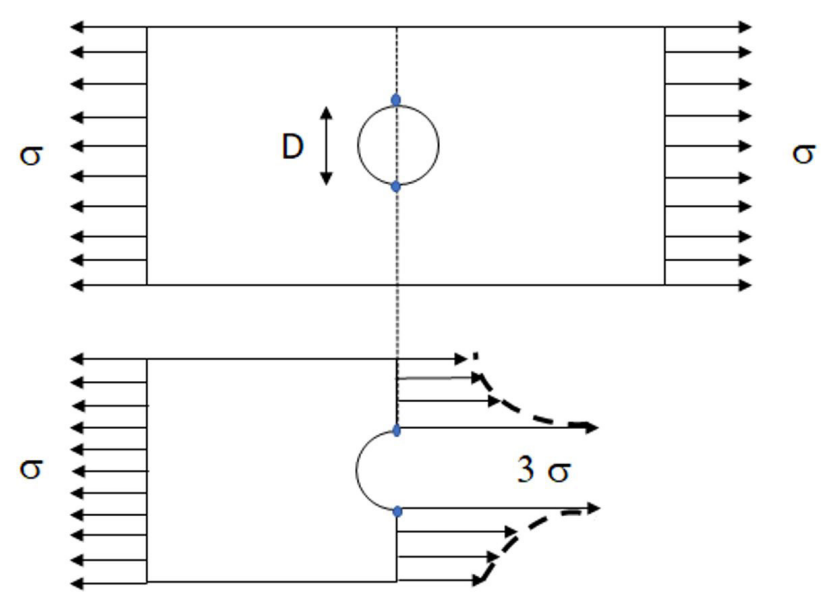

Figura I. Concentração de tensão para chapas com descontinuidade circular. $D$ é o diâmetro de furo. $\sigma$ é a tensão nominal. Os pontos em azul representa a tensão máxima. 
relacionando a transformação martensítica com estes tipos de esforços e concentradores de tensão, e em muitos casos, na prática, estes aços estão submetidos a este carregamento. Assim, este trabalho tem o objetivo de contribuir para a literatura sobre o tema em questão.

\section{METODOLOGIA}

\section{I Materiais}

O material estudado foi o AISI 304L, de composição química apresentada na Tabela I. Foram confeccionados 7 corpos de prova em 3 geometrias diferentes, A, B e C, apresentadas na Figura 2, a partir de uma chapa laminada de Imm de espessura, a qual foi cortada e posteriormente usinada por fresamento com controle de velocidade de corte, além disso foram feitos descontinuidades circulares de $2 \mathrm{~mm}$ de diâmetro em suas regiões centrais, por eletroerosão. As amostras foram nomeadas baseadas em suas geometrias, como: AI, BI, B2, B3, CI, C2 e C3.

\subsection{Métodos}

\subsection{Amostras sem descontinuidade circular}

Um corpo de prova com as mesmas dimensões apresentadas na Figura 2c, apenas sem descontinuidade circular foi ensaiado em tração monotônica, para investigar - comportamento mecânico neste tipo de carregamento. Uma máquina de tração EMIC GR 044, com capacidade máxima de $20 \mathrm{kN}$ e taxa de deformação de I,7I mm/minuto foi usada. Nessa máquina a carga é medida por transdutor. A deformação foi medida através de um extensômetro acoplado à amostra. Esse extensômetro possui um limite de abertura de $25 \mathrm{~mm}$, razão pela qual quando a base de medida do corpo-de-prova alongou-se mais do que $25 \mathrm{~mm}$, ele foi retirado, e o ensaio prosseguiu, medindo somente carga. Os valores de limite de escoamento, limite de resistência à tração e coeficiente de encruamento foram obtidos para o ensaio monotônico.

Uma outra amostra com as mesmas dimensões apresentadas na Figura 2a, apenas sem descontinuidade circular foi ensaiada em fadiga, no modo tração-tração, com freqüência de I Hz, temperatura ambiente, e tensão máxima de $600 \mathrm{MPa}$ (entre o limite de escoamento e de resistência à tração obtidos para o ensaio monotônico), a fim de se obter o comportamento do aço $304 \mathrm{~L}$ submetido ao ensaio de fadiga. $O$ ensaio foi realizado na máquina servohidráulica Instron modelo 880 I, com capacidade para $100 \mathrm{KN}$ de carga. Durante todo o ensaio do corpo de prova sem descontinuidade circular, a sonda do ferritoscópio Fischer FMP30 com capacidade mínima de detecção de $0,3 \%$ de martensita esteve acoplada ao seu centro, a fim de que fosse possível obter os dados referentes à evolução da fração volumétrica de martensita $\alpha^{\prime}$ em função do número de ciclos, in situ.

\subsubsection{Amostras com descontinuidade circular}

As amostras, Figura 2, foram submetidas a carregamentos cíclicos através de ensaio de fadiga, no modo tração-tração, por controle de deformação, à temperatura ambiente, executado pela máquina servohidráulica Instron modelo $880 \mathrm{I}$, descrita anteriormente.

As amostras AI, BI e B2 foram ensaiadas em diferentes frequências, I, 0,2 e $10 \mathrm{~Hz}$, respectivamente, e com o

Tabela I. Composição química do aço inoxidável austenítico 304L

\begin{tabular}{|c|c|c|c|c|c|c|c|c|c|}
\hline Elemento & C & Mn & Si & $\mathbf{P}$ & $\mathbf{S}$ & $\mathrm{Cr}$ & $\mathbf{N i}$ & Mo & Al \\
\hline Peso \% & 0,018 & 1,27 & 0,479 & 0,0303 & 0,0015 & 18,36 & 8,02 & 0,026 & 0,0032 \\
\hline Elemento & $\mathrm{Cu}$ & Co & V & $\mathbf{N b}$ & $\mathbf{P b}$ & B & $\mathrm{Ti}$ & Sn & W \\
\hline Peso\% & 0,043 & 0,102 & 0,042 & 0,007 I & 0,001 & 0,006 & 0,0018 & 0,0044 & 0,015 \\
\hline
\end{tabular}

Fonte: Aperam Inox América do Sul S/A.
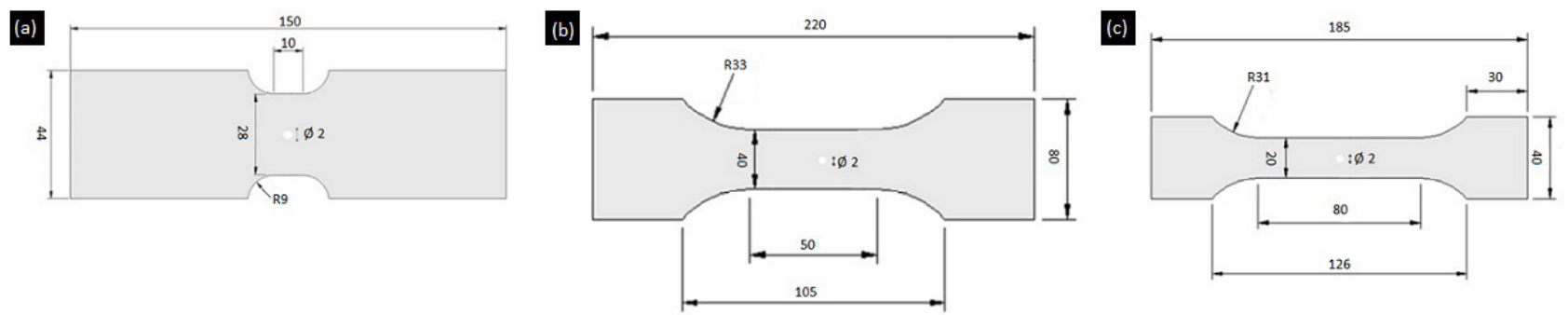

Figura 2. Geometria dos corpos de prova (a) modelo A (b) modelo B (c) modelo C. 
mesmo grau de deformação, as demais foram ensaiadas em IHz e com diferentes graus de deformação, Tabela 2.

O objetivo foi obter uma deformação localizada na zona plástica das amostras, região próxima aos concentradores de tensão. Dessa forma baseado na aplicação de algumas constantes, sendo elas, K', coeficiente de resistência cíclica, n', expoente de endurecimento por deformação cíclica, E, módulo de elasticidade cíclico e $\mathrm{K}_{\mathrm{f}}$, fator de concentração de tensão dinâmico, nas Equações I e 2, obteve-se os valores de tensões e deformações aplicadas. Onde s é a tensão local e $\sigma$ é a tensão nominal. As constantes foram obtidas através da curva tensão-deformação cíclica para o aço 304L, apresentada no trabalho de Colin [II]. A Tabela 2 apresenta as etapas do ensaio para cada amostra.

$$
\begin{aligned}
& s=K^{\prime} \times e^{n^{\prime}} \\
& \sigma=\frac{[(s \times e) E]^{1 / 2}}{K_{f}}
\end{aligned}
$$

As tensões obtidas, Tabela 2, estão entre os valores de limite de escoamento e limite de resistência a tração apresentados no ensaio de tração monotônico. E por isso o ensaio de fadiga é de baixo ciclo, ou fadiga controlada por deformações cíclicas [12].

Os corpos de prova com descontinuidade circular não tiveram a sonda do ferritoscópio acoplada a eles, pois com a deformação, a sonda se movia da zona de

\begin{tabular}{|c|c|c|c|c|}
\hline Amostra & $\begin{array}{c}\text { Tensão } \\
\text { Nominal } \\
\text { (MPa) }\end{array}$ & e & $\begin{array}{l}\text { Quantidade } \\
\text { de ciclos }\end{array}$ & $\mathbf{f}(\mathrm{Hz})$ \\
\hline \multirow[t]{3}{*}{ Amostra Al } & 381 & 0,01 & 2000 & I \\
\hline & 500 & 0,015 & 2000 & I \\
\hline & 606 & 0,020 & 1000 & I \\
\hline \multirow[t]{3}{*}{ Amostra BI } & 367 & 0,01 & 185 & 0,2 \\
\hline & 482 & 0,015 & 95 & 0,2 \\
\hline & 585 & 0,020 & 45 & 0,2 \\
\hline \multirow[t]{3}{*}{ Amostra B2 } & 367 & 0,01 & 40 & 10 \\
\hline & 482 & 0,015 & 40 & 10 \\
\hline & 585 & 0,020 & 40 & 10 \\
\hline \multirow[t]{4}{*}{ Amostra B3 } & 367 & 0,01 & 40 & 1 \\
\hline & 482 & 0,015 & 40 & I \\
\hline & 585 & 0,020 & 40 & I \\
\hline & 679 & 0,025 & 40 & I \\
\hline \multirow[t]{2}{*}{ Amostra Cl } & 383 & 0,01 & 40 & 1 \\
\hline & 502 & 0,015 & 40 & I \\
\hline \multirow[t]{3}{*}{ Amostra C2 } & 383 & 0,01 & 40 & I \\
\hline & 502 & 0,015 & 40 & I \\
\hline & 609 & 0,020 & 40 & I \\
\hline \multirow[t]{4}{*}{ Amostra C3 } & 383 & 0,01 & 40 & I \\
\hline & 502 & 0,015 & 40 & I \\
\hline & 609 & 0,020 & 40 & I \\
\hline & 707 & 0,025 & I3 (rompeu) & I \\
\hline
\end{tabular}

Tabela 2. Etapas dos ensaios de fadiga para cada amostra interesse, e desse modo a área analisada não seria aquela em torno da descontinuidade circular. Após os ensaios, as amostras foram cortadas em suas regiões centrais, em seguida foram feitas as medições de fração volumétrica de martensita via ferritoscopia. Mediu-se a partir da borda da descontinuidade circular e a cada $1 \mathrm{~mm}$ até a extremidade da amostra, a fim de analisar a variação na fração volumétrica de martensita conforme o afastamento do concentrador de tensão.

\subsubsection{Preparação metalográfica}

Uma amostra como recebida (CR), foi lixada com lixas d'água de carbeto de silício de granulometria de 320, 400, 600, 800, 1000, I 200 e I 500 mesh em uma lixadeira metalográfica sob refrigeração à água. Em seguida foram polidas em uma politriz com pano para polimento com alumina em 3 etapas, solução de I, 0,3 e 0,05 $\mu \mathrm{m}$, respectivamente. Antes e após o procedimento metalográfico, foi utilizado o ferritoscópio para verificar se a preparação metalográfica influenciou na transformação martensítica. Foi verificado uma mudança de valor menor que 0,5\% na quantidade de martensita, indicando que não houve transformação de fase no processo de preparação da amostra. A fim de visualizar a austenita na $C R$, foi feito o ataque eletrolítico da amostra em solução aquosa de ácido nítrico ( 60 vol\% $\mathrm{HNO}_{3}$ e 40 vol\% $\left.\mathrm{H}_{2} \mathrm{O}\right)$. O potencial aplicado foi de I,0 V durante 8 minutos para revelar os contornos dos grãos austeníticos [2]. O tamanho de grão austenítico, $\lambda$, foi obtido pelo método dos interceptos [13], Equação 3.

$$
\lambda=\frac{L_{T}}{N}
$$

Onde $L_{T}$ é o comprimento total de uma linha teste e $N$ é o número de interseções com contornos de grão.

Para as amostras com e sem descontinuidade circular, apresentadas nos itens 2.2. I e 2.2.2, a preparação metalográfica ocorreu como descrito no parágrafo anterior. Para revelar a fase martensítica foi utilizada uma solução contendo $0,15 \mathrm{~g}$ de metabissulfito de sódio diluídos em $100 \mathrm{~mL}$ de água destilada, acrescido da mistura de $10 \mathrm{~mL}$ de ácido clorídrico com $100 \mathrm{~mL}$ de água destilada [14].

As análises microscópicas foram realizadas com o auxílio do microscópio óptico Olympus BX5IM, e as micrografias foram obtidas pelo software Olympus Stream Basic I.9. As micrografias foram obtidas a uma distância de aproximadamente $2 \mathrm{~mm}$ da descontinuidade circular, devido a deformação e afundamento na borda da descontinuidade, dificultando o foco, só sendo possível a obtenção das micrografias a partir dessa distância. Como a caracterização do teor de martensita por microscopia óptica não resulta em precisão adequada, as micrografias foram analisadas de forma qualitativa. 


\section{RESULTADOS E DISCUSSÃO}

\section{I Ensaio Monotônico e Ensaio de Fadiga na Amostra Sem Descontinuidade Circular}

Na Figura 3 é apresentada a curva tensão versus deformação do material na amostra sem descontinuidade circular. Pode-se notar que ocorre um encruamento significativo. $\mathrm{Na}$ deformação de $0,2 \%$, obteve-se o limite de escoamento de aproximadamente $320 \mathrm{MPa}$. O limite de resistência foi de $712 \mathrm{MPa}$. Devido à limitação de abertura do extensômetro, o máximo de alongamento que pôde ser medido foi de $50 \%$ de alongamento. Porém após a retirada do extensômetro até a ruptura, o corpo de prova continuou a se deformar mais um pouco. $O$ valor do coeficiente de encruamento, $n$, ficou em torno de 0,3 , indicando endurecimento do material

Através do ensaio de fadiga realizado em uma amostra sem descontinuidade circular, foram obtidos os laços de histerese, oriundos do gráfico tensão-deformação cíclica. Para melhor visualização são apresentados apenas os: $1^{\circ}, 10^{\circ}, 20^{\circ}, 30^{\circ}, 40^{\circ}, 50^{\circ}, 60^{\circ}, 70^{\circ}, 80^{\circ}, 90^{\circ}$ e $100^{\circ}$ ciclos, respectivamente na Figura 4. A largura do laço de histerese é a medida da deformação plástica, o que é a causa da transformação martensítica. Percebe-se que depois de certa quantidade de ciclos a deformação se satura e os laços de histerese passam a ficar sobrepostos, não havendo a necessidade de um elevado número de ciclos (entre 30 e 100 ciclos) para se obter uma deformação em torno de 0,10 e uma fração volumétrica de martensita entre 6 e 7\%, Figura 5. A partir do $30^{\circ}$ ciclo, a fração de martensita permanece praticamente constante, Figura 5. Como descrito no item 2.2.I, para o corpo de prova sem descontinuidade circular, o ferritoscópio esteve acoplado ao corpo de prova durante todo o ensaio e a aquisição de dados da fração volumétrica de martensita transformada foram feitas automaticamente a cada I segundo. A Figura 5 apresenta os valores de fração volumétrica de martensita em função do número de ciclos.

\subsection{Ensaio de Fadiga nas Amostras com Descontinuidade Circular}

A Figura 6 apresenta os dados referentes ao comparativo das frações volumétricas de martensita das amostras AI, BI e B2 em cada deformação para as diferentes frequências apresentadas na Tabela 2.

A Figura 6 apresenta que a fração volumétrica de martensita aumenta ao passo que a deformação plástica causada pelas deformações cíclicas aumenta $(0,01$ para as amostras apresentadas na Figura 6a até 0,020 para as amostras apresentadas na Figura 6c) e a porcentagem de martensita diminui conforme se afasta do concentrador de tensão. Comportamento apresentado em todas as Figuras, $6 \mathrm{a}$ a $6 \mathrm{c}$, desde a borda até a distância de $10 \mathrm{~mm}$. As Figuras $6 \mathrm{a}-6 \mathrm{c}$ mostram que na borda da descontinuidade circular e quanto mais próximo dele os resultados seguem o descrito na literatura,

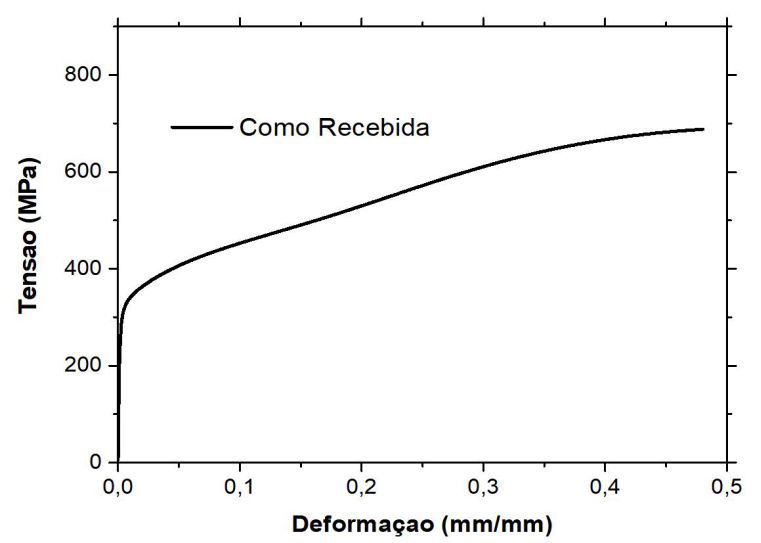

Figura 3. Curva Tensão-Deformação para material sem descontinuidade circular.

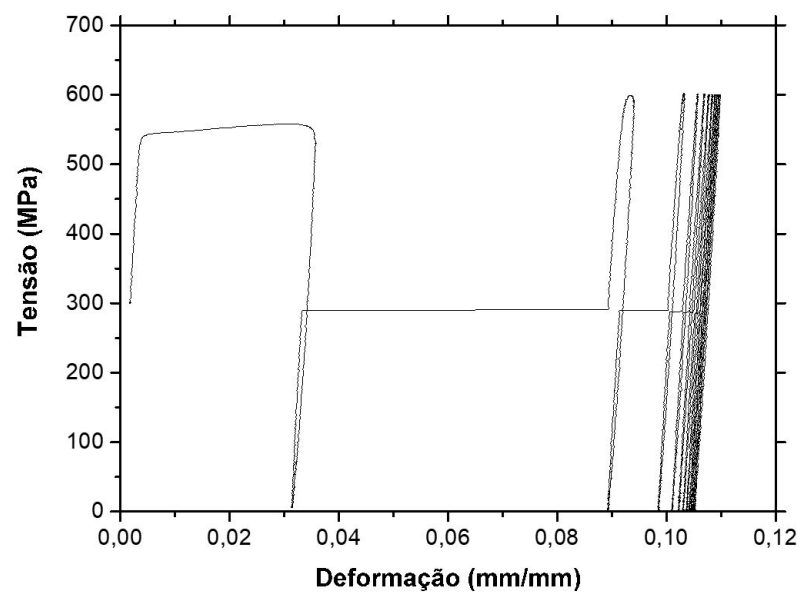

Figura 4. Laços de histerese para amostra sem descontinuidade circular, ensaiada para tensão máxima de $600 \mathrm{MPa}$ e 100 ciclos.

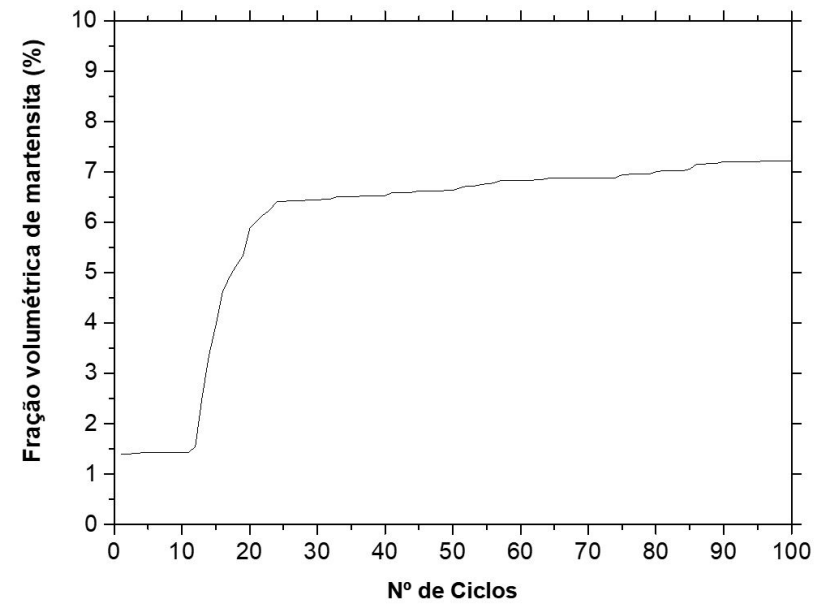

Figura 5. Fração de martensita em função do número de ciclos. Amostra ensaiada para tensão máxima de $600 \mathrm{MPa}$ e 100 ciclos.

ou seja, em frequências menores (por exemplo $0,2 \mathrm{~Hz}$ ) as frações volumétricas de martensita são maiores [3]. Provavelmente, devido a baixa temperatura gerada em baixa 


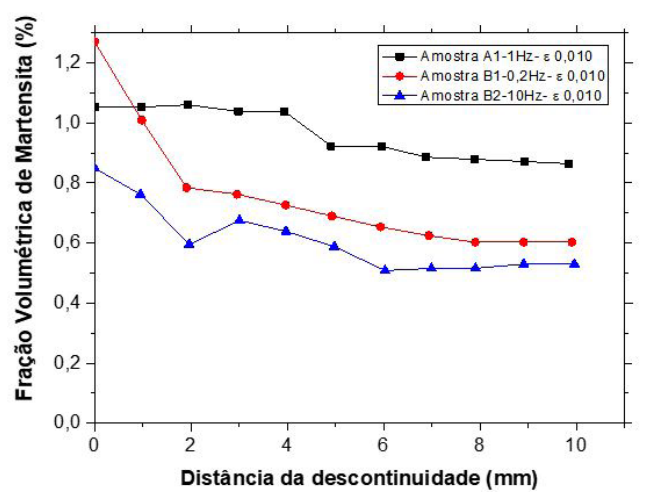

(a)

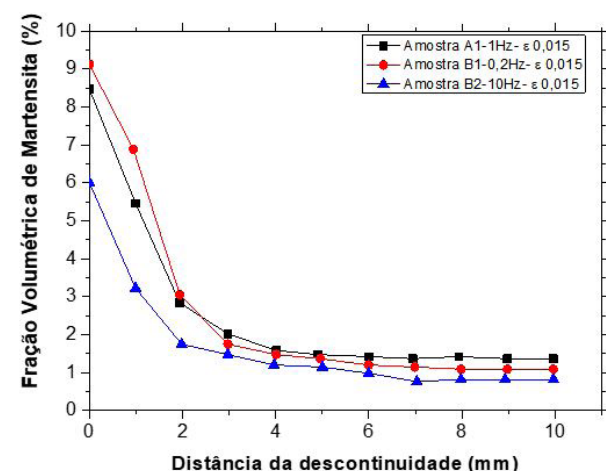

(b)

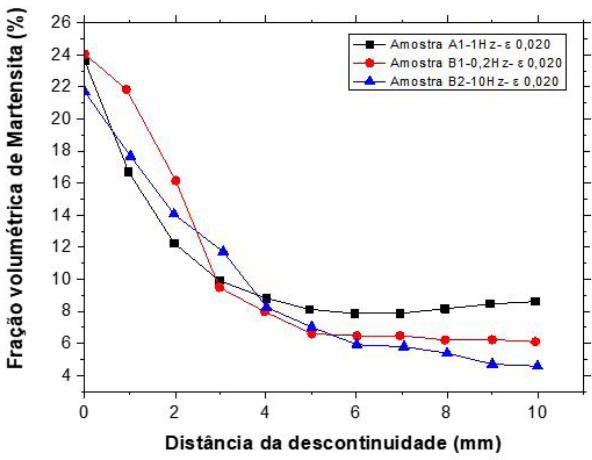

(c)

Figura 6. Fração de martensita em relação à distância da descontinuidade circular para as amostras $\mathrm{AI}$, BI e B2 (ensaiadas nas frequências de I, 0,2 e $10 \mathrm{~Hz}$, respectivamente) com deformação de (a) 0,010 (b) 0,015 (c) 0,020 .

frequência. Favorecendo assim a formação de martensita. Forma-se martensita por deformação porque a energia necessária para esta transformação é menor que a energia necessária para formar maclas de deformação. Porém, ao passo que se distancia da descontinuidade circular ocorrem pequenas oscilações e esses valores tendem ao mesmo valor final de martensita, principalmente para as deformações de 0,015 e 0,020 , Figuras $6 \mathrm{~b}$ e $6 \mathrm{c}$. Acredita-se que se deva ao efeito da descontinuidade circular e/ou que a diferença entre as frequências não seja tão alta para interferir na temperatura conforme ocorre o distanciamento da descontinuidade circular.

A Figura 7 apresenta os resultados comparativos das frações volumétricas de martensita das amostras $\mathrm{Cl}, \mathrm{C} 2, \mathrm{C} 3$ (rompeu-se) e B3, com diferentes deformações e mesma frequência $(\mathrm{IHz})$.

$\mathrm{Na}$ Figura 7, para a amostra $\mathrm{Cl}$ a deformação é de 0,015 e a máxima fração volumétrica de martensita é $8,3 \%$. Esse valor aumenta significativamente na amostra seguinte, $\mathrm{C} 2$, onde a deformação é de 0,020 , chegando ao valor máximo de $26,6 \%$. Já em C3, com 0,025 de deformação a máxima fração volumétrica de martensita é de $31,4 \%$, mas diferentemente das outras amostras a fração volumétrica de martensita entre a borda da descontinuidade circular e a extremidade diminui muito pouco, com um mínimo de $26,6 \%$, mantendo uma determinada uniformidade. Isto se

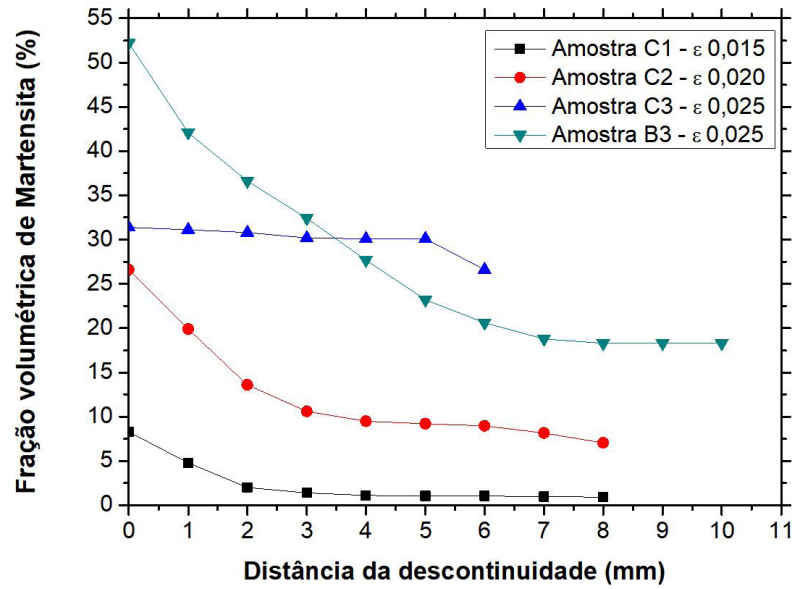

Figura 7. Fração de martensita em relação a distância da descontinuidade circular para as amostras $\mathrm{Cl}, \mathrm{C} 2, \mathrm{C} 3$ e B3 com deformação de 0,015, $0,020,0,025$ e 0,025, respectivamente.

deve ao fato da amostra ter sofrido ruptura. Ou seja, ocorreu deformação localizada, gerando martensita. A amostra B3, teve a mesma deformação que $\mathrm{C} 3$, porém ela não sofreu ruptura, sua fração volumétrica de martensita atingiu um valor máximo de $52,2 \%$. 


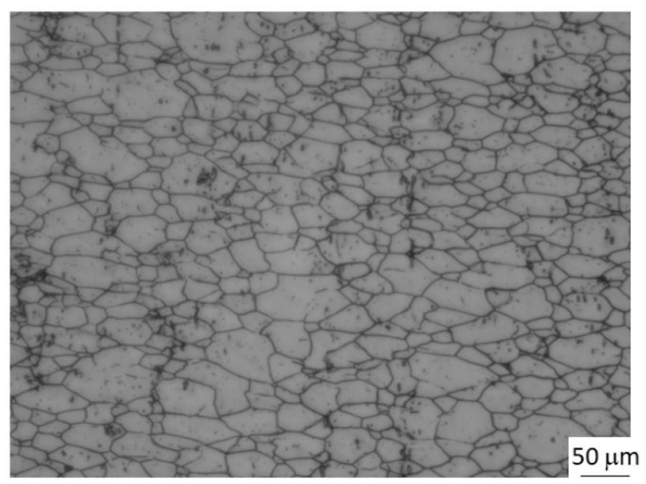

(a)

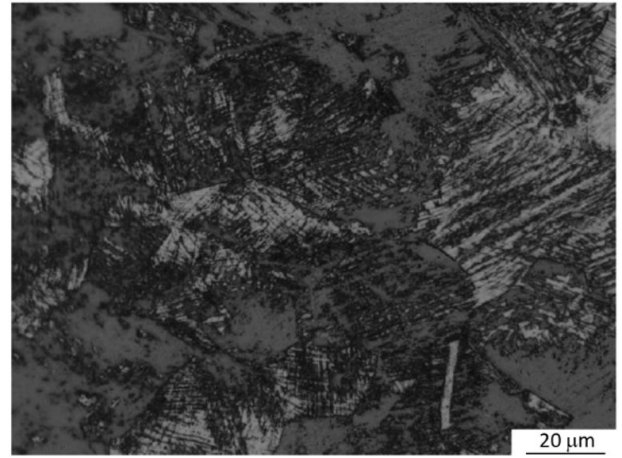

(b)

Figura 8. Micrografia das amostras (a) Como Recebida; (b) Amostra deformada, apresentando áreas: escura, referente a fase martensita e clara referente a austenita.

\subsection{Análise por Microscopia Óptica}

A Figura 8a apresenta a micrografia da amostra como recebida. Na Figura 8a é apresentada os contornos de grãos austeníticos. Através da Equação 3 foi determinado o tamanho médio de grão de aproximadamente $30 \mu \mathrm{m}$. A Figura $8 \mathrm{~b}$ apresenta a microestrututra mais próxima da descontinuidade circular após o teste com a amostra B3, com deformação de 0,025 . Na Figura 8 b observa-se a fase martensítica, que se apresenta em formas de ripas e em "cluster percolados". Morfologia similar para martensita foi encontrado por Talonen para altas deformações [2]. Como a medição por metalografia quantitativa da fração volumétrica de martensita via microscopia ótica não tem uma precisão adequada, a Figura 8 pode ser avaliada de forma qualitativa. A figura $8 \mathrm{~b}$ apresenta a condição aonde se formou mais martensita em todos os testes apresentados na Tabela 2. A fração volumétrica de martensita foi estimada via Ferritoscopia, Figuras 6 e 7. Esta técnica já se mostrou eficaz para estimar a porcentagem de martensita em amostras deformadas $[2,14]$

\section{CONCLUSÕES}

Com base nos resultados e discussão obtidos para - aço inoxidável austenítico 304L, ensaiado ciclicamente, com e sem descontinuidade circular, pode-se concluir que:

- Após o ensaio de fadiga realizado em uma amostra sem descontinuidade circular, obteve-se que depois de certa quantidade de ciclos a deformação se satura e os laços de histerese passam a ficar sobrepostos, não havendo a necessidade de um elevado número de ciclos para se obter uma deformação em torno de 0,10 e uma fração volumétrica de martensita entre 6 e 7\%;
- Após ensaio de fadiga em diferentes frequências para amostras com descontinuidade circular, notou-se que em frequências menores, por exemplo $0,2 \mathrm{~Hz}$, as amostras apresentam próxima a descontinuidade circular maiores frações volumétricas de martensita, pois o trabalho da deformação é menor, sendo assim sofrem menos com o efeito da temperatura que tende a inibir a transformação. Ao passo que ao se distanciar da descontinuidade circular as frações volumétricas de martensita tendem ao mesmo valor final;

- Após ensaio de fadiga na mesma frequência, I Hz, e diferentes deformações, para amostras com descontinuidade circular, a fração volumétrica de martensita aumenta conforme se aumenta o grau de deformação, e a fração volumétrica de martensita é maior na borda da descontinuidade circular e diminui conforme o distanciamento desse local, pois a deformação é maior quão mais próximo se está da descontinuidade;

- Inicialmente a amostra é composta por grãos austeníticos de $30 \mu \mathrm{m}$ aproximadamente. Após os ensaios cíclicos, a martensita se forma e apresenta a morfologia de ripas e em maiores deformações, além das ripas, apresentam a morfologia de "cluster percolados".

\section{Agradecimentos}

Os autores agradecem a Universidade Federal Fluminense (UFF), CAPES (Coordenação de Aperfeiçoamento de Pessoal de Nível Superior), FAPERJ (Fundação de Amparo à Pesquisa do Estado do Rio de Janeiro) e ao CNPq (Conselho Nacional de Desenvolvimento Científico e Tecnológico), pelo auxílio financeiro cedido para elaboração do trabalho. 


\section{REFERÊNCIAS}

I Costa e Silva ALV, Mei PR. Aços e ligas especiais. 2. ed. São Paulo: Edgard Blucher; 2006.

2 Talonen J. Effect of strain-induced $\alpha$ '-martensite transformation on mechanical properties of metastable austenitic stainless steels [dissertation]. Espoo: Helsinki University of Technology; 2007.

3 Hecker SS, Stout MG, Staudhammer KP, Smith JL. Effects of strain state and strain rate on deformation-induced transformation in 304 stainless steel. Part I. Magnetic measurements and mechanical behavior. Metallurgical Transactions. 1982;A13:619-626.

4 Tavares SSM, Pardal JM, da Silva MJG, Abreu HFG, Silva MR. Deformation induced martensitic transformation in a 201 modified austenitic stainless steel. Materials Characterization. 2009;60:907-91 I.

5 Spencer K, Embury JD, Conlon KT, Véron M, Bréchet Y. Strengthening via the formation of strain-induced martensite in stainless steels. Materials Science and Engineering. 2004;387-389:873-88I.

6 Sales LS. Envelhecimento na martensita induzida por deformação em aços tipo AISI 30 [dissertação]. Belo Horizonte: Universidade Federal de Minas Gerais; 2006.

7 Alves JM. Análise da transformação martensítica e tensão residual em um aço inoxidável 304L [dissertação]. Rio de Janeiro: Instituto Militar de Engenharia; 2014.

8 Maier HJ, Schneeweiss O, Donth B. Kinetics of fatigue-induced phase transformation in a metastable austenitic 304L type steel at low temperatures. Scripta Metallurgica et Materialia. 1993;29:52 I-526.

9 Zhang SH, Xu Y, Cheng M, Song HW. In situ X-ray diffraction study of martensitic transformation in austenitic stainless steel during cyclic tensile loading and unloading. Scripta Materialia. 20I 2;67:77I-774.

10 Peterson RE. Stress concentration factors. New York: John Wiley \& Sons; 1974.

I I Colin J, Fatemi A, Taheri S. Cyclic hardening and fatigue behavior of stainless steel 304L. Journal of Materials Science. 20II;46(I): 145-I54.

12 Hertzberg RW. Deformation and fracture mechanics of engineering materials. New York: John Wiley \& Sons; 1976.

13 Russ JC, Dehoff RT. Practical stereology. 2. ed. New York. Kluwer Academic/Plenum Publishers; 2000.

14 Talonen J, Aspegren P, Hanninen H. Comparison of different methods for measuring strain induced $\alpha^{\prime}$-martensite content in austenitic steels. Materials Science and Technology. 2004;20:I506-I5I2.

Recebido em: 9 Maio. 2018

Aceito em: 19 Jun. 2019 